\title{
BMJ Open Translation, cross-cultural adaptation and validation of the traditional Chinese intermittent and constant osteoarthritis pain (ICOAP) questionnaire for knee osteoarthritis
}

\author{
Regina Wing Shan Sit, ${ }^{\oplus 1}$ Dicken Cheong Chun Chan, ${ }^{2}$ Wendy Wong, ${ }^{\oplus 3}$ \\ Benjamin Hon Kei Yip, ${ }^{2}$ Lyan Lai Yan Chow, ${ }^{2}$ Samuel Y S Wong ${ }^{4}$
}

To cite: Sit RWS, Chan DCC, Wong W, et al. Translation, cross-cultural adaptation and validation of the traditional Chinese intermittent and constant osteoarthritis pain (ICOAP) questionnaire for knee osteoarthritis. BMJ Open 2019;9:e026006. doi:10.1136/ bmjopen-2018-026006

- Prepublication history and additional material for this paper are available online. To view these files, please visit the journal online (http://dx.doi org/10.1136/bmjopen-2018026006).

Received 16 August 2018 Revised 5 February 2019 Accepted 12 February 2019

Check for updates

(c) Author(s) (or their employer(s)) 2019. Re-use permitted under CC BY-NC. No commercial re-use. See rights and permissions. Published by BMJ.

For numbered affiliations see end of article.

Correspondence to

Professor Regina Wing Shan Sit; reginasit@cuhk.edu.hk

\section{ABSTRACT}

Objectives To translate and culturally adapt the Intermittent and Constant Osteoarthritis and Pain (ICOAP) measure to a traditional Chinese version, and to study its psychometric properties in patients with knee osteoarthritis (KOA).

Method The ICOAP was translated and cross-culturally adapted into traditional Chinese according to the recommended international guidelines. A total of 110 participants with KOA in Hong Kong were invited to complete the traditional Chinese ICOAP (tChICOAP), the Chinese Western Ontario and McMaster Universities Osteoarthritis Index (WOMAC) pain subscale and the Chinese Short form of Health Survey (SF-12v2). Psychometric evaluations included content validity, construct validity, internal consistency and test and retest reliability.

Results All participants completed the tChICOAP questionnaire without missing items. The content validity index of all items ranged from $80 \%$ to $100 \%$. The tChICOAP total pain and subscale scores had excellent internal consistency with Cronbach's alpha value (0.902-0.948) and good corrected item-total subscale correlations. It had high test and retest reliability (intraclass correlations $0.924-0.960$ ). The tChICOAP constant, intermittent and total pain scores correlate strongly with the WOMAC pain subscale $(r=0.671,0.678$ and 0.707 , respectively, $p<0.001)$. The tChICOAP intermittent and total scores correlate strongly with SF-12v2 physical component score $(r=-0.590$ and -0.558 , respectively, $\mathrm{p}<0.001$ ).

Conclusions The tChICOAP is a reliable and valid instrument to measure the pain experience of Chinese patients with KOA.

\section{INTRODUCTION}

Knee osteoarthritis (KOA) is a major cause of pain and disability contributing to the healthcare service burden worldwide. ${ }^{1}$ Pain in KOA is multi-dimensional. While pain intensity is commonly assessed by a numerical or Visual Analogue Scale (VAS), this
Strengths and limitations of this study

- This is the first study to validate the Traditional Chinese version of the Intermittent and Constant Osteoarthritis and Pain (tChICOAP) questionnaire.

- The translation and validation of the TChICOAP followed a robust methodology.

- The content validity index of the ICOAP was first reported in this study.

- Responsiveness of the tChICOAP was not tested.

presents limitations, as it does not consider the dynamic nature of pain. ${ }^{2}$ It is established that the characteristics of pain often change over time and the experience of chronic pain with episodic flares is often unpredictable and emotionally draining. ${ }^{3}$ Thus, The Osteoarthritis Research Society International (OARSI) has identified 'phenotyping' of OA pain as a research priority to 'better target pain therapies to individual patients'. ${ }^{4}$

The Intermittent and Constant Osteoarthritis and Pain (ICOAP) measure was developed by an international working group under the guidance of OARSI and Outcome Measures in Rheumatology Clinical Trials (OMERACT).$^{5}$ The original English language ICOAP was used to widely in research to measure pain experience. It captures pain intensity as well as related distress and the impact of OA pain on quality of life. ${ }^{6}{ }^{7}$ It has been tested to have good psychometric properties in multiple languages including Turkish, Portuguese, German and Greek. ${ }^{8-11}$ In view of the ever-increasing trend for multinational studies and international cooperation among medical organisations, there is a compelling need to increase the applicability of this instrument in the Chinese population. 


\begin{tabular}{|c|c|}
\hline Characteristics & Total sample $(n=110)$ \\
\hline Age (years) & $62.2 \pm 5.7$ \\
\hline \multicolumn{2}{|l|}{ Gender } \\
\hline Male & $28(25.5 \%)$ \\
\hline Female & $82(74.5 \%)$ \\
\hline $\mathrm{BMI}^{*}$ & $24.68 \pm 3.68$ \\
\hline WOMAC pain score, mean (SD) & $169.70(124.37)$ \\
\hline SF-12v2 (PCS), mean (SD) & $39.22(9.50)$ \\
\hline SF-12v2 (MCS), mean (SD) & $48.79(9.29)$ \\
\hline Duration of knee pain* & $8.76 \pm 6.70$ \\
\hline \multicolumn{2}{|l|}{ Kellgren and Lawrence Grading† } \\
\hline Grade 1 & $17(16.5 \%)$ \\
\hline Grade 2 & $42(40.8 \%)$ \\
\hline Grade 3 & $36(35 \%)$ \\
\hline Grade 4 & $8(7.7 \%)$ \\
\hline
\end{tabular}

*Missing six sets of data.

†Missing seven sets of data.

BMI, Body Mass Index; MCS, mental component scores; PCS, physical component score; SF-12, Short form of Health Survey-12; WOMAC, Western Ontario McMaster University Osteoarthritis Index.

A simplified Chinese version of ICOAP has been published by Zhang et al. ${ }^{12}$ While simplified Chinese is the official language used in the People's Republic of China, Singapore and Malaysia, traditional Chinese is the common language used in Hong Kong, Taiwan, Macau and overseas Chinese communities. The aims of this study were to translate and culturally adapt ICOAP into traditional Chinese, to test the psychometric properties including the internal consistency, the construct validity, and the test and retest reliability of the traditional Chinese ICOAP (tChICOAP).

\section{MATERIAL AND METHODS \\ Patient and public involvement}

Patients were not involved in the design and conception of this study. Patients were not invited to contribute to the writing or editing of this document for readability and accuracy.

\section{Step 1: Translation and cross-cultural adaptation}

We followed the steps as suggested by the developer of the ICOAP in conducting the translation of the tChICOAP. ${ }^{13}$ In the first step, one English translator and one orthopaedic surgeon, who are native in Chinese and fully bilingual in English, translated independently the original English version into Traditional Chinese (Cantonese). In the second step, a single preliminary version was obtained after a simple consensus meeting with the two translators. In the third step, a backward translation was performed by an independent bilingual native English speaker, blinded to the English original version. In the fourth step, a multidisciplinary expert committee was formed, which consisted of the initial two translators, one orthopaedic surgeon, one physiotherapist and one co-investigator (WW) who is very familiar with cross-cultural adaptation. The committee reviewed all the versions, discussed the phrasing of the target-language version and reached consensus on the final version of tChICOAP. In the fifth step, the final version was pretested for cognitive debriefing with 10 native Chinese participants with KOA. These participants completed the questionnaire in the presence of a study coordinator and each question was discussed to check whether it is fully acceptable and comprehensible. The cognitive debriefing was reviewed by the principal investigator (RS) and the co-investigator (WW) and the initial translation was modified accordingly.

\section{Step 2: Psychometric testing using a cross-sectional cohort Participants}

A total of 110 participants were recruited through poster advertisement and referrals by primary care physicians between July and December 2017 in the General Outpatients Clinics (GOPCs) in the New Territories East region of Hong Kong. Eligibility was screened by a trained research assistant using a phone interview and potential eligible participants were invited to meet the principal investigator at the study site, which is a teaching clinic operated by the Chinese University of Hong Kong. Written inform consents were obtained from all participants.

The inclusion criteria included participants with the diagnosis of primary knee OA based on clinical and radiological criteria as defined by the American Rheumatology Association, aged $\geq 45$ to $\leq 75$ years, and with knee pain for at least 3 months. ${ }^{14}$ Participants were excluded if they were not Cantonese speaking, they had other disease of the bones and joints of the lower limbs, or they had neurological disease, back problems or widespread pain, or an inability or unwillingness to complete the questionnaire.

\section{Research instrument}

The ICOAP: This is an 11-item questionnaire divided into two domains; a 5-item scale for constant pain and a 6-item scale for intermittent pain (so called 'pain that comes and goes'). The pain score is rated by pain intensity, frequency, impact on mood, sleep and quality of life. ${ }^{5}$ Previous study has supported the use of constant and intermittent subscales as one-dimensional measures of pain. ${ }^{15}$ Each score is rated from 0 to 4 , and the sum is further standardised to a range of values from 0 to 100 .

The Chinese WOMAC: The WOMAC is a disease-specific questionnaire recommended to be used during osteoarthritis clinical trials. ${ }^{16}$ It consists of 24 self-reported items, including knee pain (5 items), stiffness (2 items), and function (17 items). Each item is graded either on a five-point Likert scale or on a $100 \mathrm{~mm}$ VAS. In this study, we used the VAS to rate the pain subscale. ${ }^{17}$ The WOMAC pain subscale is recommended by the developer of ICOAP to test on the construct validity. ${ }^{5}$ The total score 
Table 2 間歇性和持續性骨關節炎疼痛的測量 (ICOAP): 膝關節版本 (A measure of Intermittent and Constant Osteoarthritis Pain, ICOAP: KNEE Version)

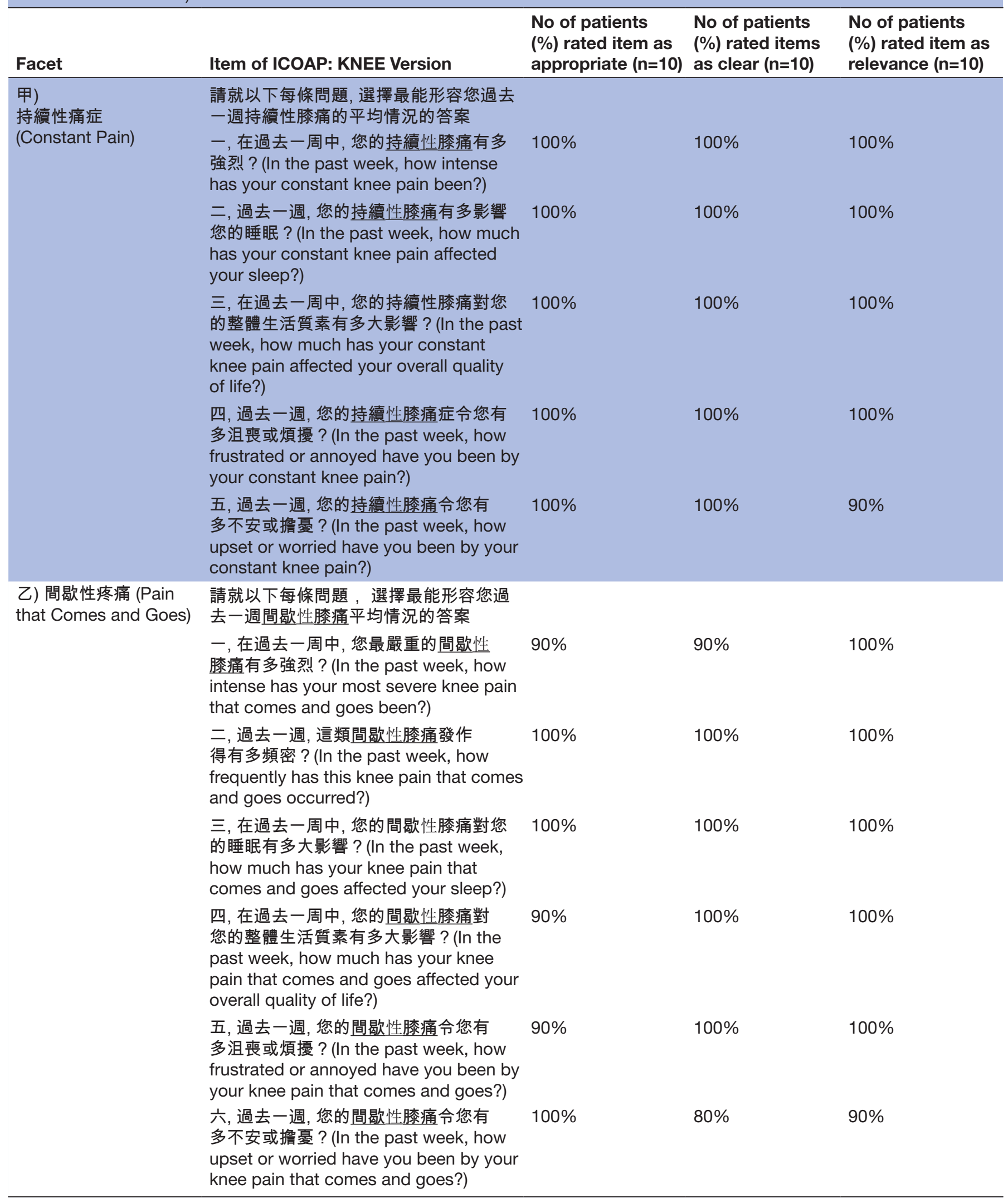

will be determined by adding corresponding items for each dimension. We use the validated Chinese WOMAC in this study. ${ }^{18}$
The Chinese Short form of Health Survey (SF-12v2): This consists of 12 items measuring eight subscales on physical functioning, role physical, bodily pain, general 
Table 3 Internal consistency and reliability of the Intermittent and Constant Osteoarthritis and Pain subscales and total pain

\begin{tabular}{|c|c|c|c|c|c|c|}
\hline \multirow[b]{2}{*}{ Scale } & \multicolumn{2}{|c|}{ Mean score (SD) } & \multirow{2}{*}{$\begin{array}{l}\text { Intra- class correlation } \\
(95 \% \mathrm{Cl})\end{array}$} & \multirow{2}{*}{$\begin{array}{l}\text { Cronbach's } \\
\text { a coefficient }\end{array}$} & \multirow[b]{2}{*}{ SEM } & \multirow{2}{*}{$\begin{array}{l}\text { Minimal } \\
\text { detectable change }\end{array}$} \\
\hline & First & Second & & & & \\
\hline Constant & $30.23(21.11)$ & 31.18 (20.62) & 0.959 (0.940 to 0.972$)$ & $0.934^{*}$ & 4.27 & 11.85 \\
\hline Total & $34.52(18.54)$ & $34.21(18.77)$ & 0.960 (0.941 to 0.972$)$ & & 3.71 & 10.28 \\
\hline
\end{tabular}

${ }^{\star}$ Excellent reliability $>0.75$.

health, vitality, social functioning, and emotional and mental health. ${ }^{19}$ The sub-scale scores can be summarised into physical component (PCS) and mental component (MCS) scores. The measure has strong construct validity, responsiveness and clinometric profile. Study has shown that the Chinese SF-12 explained $88 \%$ and $90 \%$ of the variance of the SF-36 PCS and MCS scores, respectively. The correlations between the corresponding SF-36 and SF-12 summary scores all reached the expected standard of 0.9 and the effect size differences between the standard SF-36 and SF-12 scores were less than $0.3 .{ }^{20} \mathrm{We}$ hypothesised that the ICOAP total and subscales would correlate strongly with the SF-12v2 PCS.

ICOAP, WOMAC pain subscale and SF-12v2 are self-reported questionnaires. Participants completed the questionnaires with the help of a research assistant at the study site. The interviews were repeated by the same research assistant 5 days later at the same study site. An interval of 5 days was chosen after considering the possible change in pain score with time; we believe the memory effect should be minimal given that our participants were mostly older people with KOA. Age, sex, body mass index, duration of

Table 4 Correlation of each item and total Intermittent and Constant Osteoarthritis and Pain scores ( $n=110)$

\begin{tabular}{|c|c|c|c|c|}
\hline ICOAP items & $\begin{array}{l}\text { Corrected } \\
\text { item-total } \\
\text { coefficients }^{*}\end{array}$ & $\begin{array}{l}\text { Corrected } \\
\text { item-total } \\
\text { coefficients } †\end{array}$ & $\begin{array}{l}\text { Cronbach's } \alpha \text { if } \\
\text { item deleted* }\end{array}$ & $\begin{array}{l}\text { Cronbach's } \alpha \text { if } \\
\text { item deleted } \dagger\end{array}$ \\
\hline \multicolumn{5}{|l|}{ Constant pain subscale } \\
\hline $\begin{array}{l}\text { 1. In the past week, how intense has your constant } \\
\text { knee pain been? }\end{array}$ & 0.853 & 0.802 & 0.913 & 0.941 \\
\hline $\begin{array}{l}\text { 2. In the past week, how much has your constant } \\
\text { knee pain affected your sleep? }\end{array}$ & 0.697 & 0.698 & 0.940 & 0.945 \\
\hline $\begin{array}{l}\text { 3. In the past week, how much has your constant } \\
\text { knee pain affected your overall quality of life? }\end{array}$ & 0.869 & 0.833 & 0.910 & 0.940 \\
\hline $\begin{array}{l}\text { 4. In the past week, how frustrated or annoyed have } \\
\text { you been by your constant knee pain? }\end{array}$ & 0.855 & 0.847 & 0.912 & 0.940 \\
\hline $\begin{array}{l}\text { 5. In the past week, how upset or worried have you } \\
\text { been by your constant knee pain? }\end{array}$ & 0.852 & 0.850 & 0.914 & 0.940 \\
\hline $\begin{array}{l}\text { 7. In the past week, how frequent has this knee pain } \\
\text { that comes and goes occurred? }\end{array}$ & 0.620 & 0.623 & 0.900 & 0.948 \\
\hline $\begin{array}{l}\text { 8. In the past week, how much has your knee pain } \\
\text { that comes and goes affected your sleep? }\end{array}$ & 0.680 & 0.739 & 0.892 & 0.944 \\
\hline $\begin{array}{l}\text { 9. In the past week, how much has your knee pain } \\
\text { that comes and goes affected your overall quality of } \\
\text { life? }\end{array}$ & 0.841 & 0.803 & 0.869 & 0.942 \\
\hline $\begin{array}{l}\text { 10. In the past week, how frustrated or annoyed have } \\
\text { you been by your knee pain that comes and goes? }\end{array}$ & 0.787 & 0.794 & 0.876 & 0.942 \\
\hline
\end{tabular}

*Generated from constant and intermittent pain subscales of ICOAP.

†Generated from the total pain score of ICOAP. 
knee pain and Kellgren-Lawrence grading of the knees were collected.

\section{Sample size}

A sample size of 10 was set for cognitive debriefing as we followed the international team for the same translation and cultural adaptation process. ${ }^{13}$ For the psychometric testing, we calculated our sample size based on an expected intra-class correlation of 0.70 , width of 0.2 of the $95 \% \mathrm{CI}$ and the number of measurement to be 2 ; with two sided type I error of $5 \%$, the target sample size was calculated to be 100. To compensate for potential dropout rate of $10 \%$, we set our enrolment target at 110 subjects. ${ }^{21}$

\section{Statistical analysis}

Content validity was evaluated with content validity index (CVI).Construct validity was evaluated using the correlation coefficients between the domain scores and total scores of tChICOAP, WOMAC pain subscale and SF-12v2; with $>0.5,0.35-0.50$ and $<0.35$ considered as strong, moderate and weak, respectively. ${ }^{18}$ Internal consistency was assessed using the Cronbach's alpha and corrected item-total scale correlations. Cronbach's alpha $\geq 0.7$ is generally regarded as acceptable for group comparison. ${ }^{22}$ Corrected item-total scale correlation between domains and their constituent item with $\geq 0.4$ was considered as acceptable. ${ }^{23}$ Test and retest reliability was assessed with an interval of 5 days in between using intra-class correlation (ICC; two-way mixed effects model); an ICC $>0.75$ is considered as excellent, $0.59-0.75$ as good, $0.40-0.58$ as fair and $<0.4$ as showing poor reliability. ${ }^{24}$ The SEM is estimated from the SD of a sample of scores at baseline and a test-retest reliability index of the measurement instrument. Minimal detectable change (MDC) was estimated from SEM and a degree of confidence. The data were entered and analysed using the SPSS V.21.0. P value $<0.05$ was considered as statically significant.

\section{RESULTS}

The demographics of 110 participants are summarised in table 1 .

\section{Cross-cultural adaptation and content validity}

Slight differences were identified in the structure of the sentences between the original and translated versions and minor adjustments were made. Two participants found it difficult to understand the difference between 'frustrated or annoyed' versus 'upset or worried' in Chinese (Cantonese) and the words were rephrased to guarantee the exact meaning. Minor modifications were made to the Chinese terms to improve the succinctness of the questionnaire (online supplementary file). The CVI on 'clarity', 'appropriateness' and 'relevance' ranged from $80 \%$ to $100 \%$ (table 2). Participants felt that the questionnaire was easy to understand, the content covered the essential pain experience and that the questions aligned well with their feelings.

\section{Internal consistency and reliability}

The internal consistency was good. The Cronbach's alpha values were $0.934,0.902$ and 0.948 for the constant pain score, the intermittent pain score and the total pain score, respectively. The corrected item-total subscale correlations ranged from 0.70 to 0.87 for the constant pain score and 0.62 to 0.84 for the intermittent pain score. It has excellent test and re-test reliability, with ICC values of 0.959 for the constant pain score and 0.924 for the intermittent score. The SEM and MDC of the tChICOAP total score are 3.71 and 10.28 , respectively (tables 3 and 4).

\section{Construct validity}

The tChICOAP constant, intermittent, and total score correlated strongly with the WOMAC pain subscale $(\mathrm{r}=0.671,0.678$ and 0.707 , respectively, $\mathrm{p}<0.001)$. The tChICOAP intermittent pain score and total pain score correlated strongly with the SF12 PCS ( $r=-0.590$ and -0.558 , respectively, $\mathrm{p}<0.001$ ), and the constant pain score correlated moderately with SF12 PCS ( $\mathrm{r}=-0.487$, $\mathrm{p}<0.001)$. Moderate correlations were found for constant, intermittent and total pain score with the SF12 MCS score $(\mathrm{r}=-0.398,-0.418$ and -0.431 , respectively, $\mathrm{p}<0.001)$ (table 5).

\begin{tabular}{|c|c|c|c|}
\hline & $\begin{array}{l}\text { SF12 Physical Component } \\
\text { Summary }\end{array}$ & $\begin{array}{l}\text { SF12 Mental Component } \\
\text { Summary }\end{array}$ & WOMAC Pain Subscale \\
\hline \multicolumn{4}{|l|}{ ICOAP } \\
\hline Constant & $-0.487(\mathrm{P}<0.001)^{\star}$ & $-0.398(P<0.001)^{\star}$ & $0.671(\mathrm{P}<0.001) \dagger$ \\
\hline Intermittent & $-0.590(P<0.001) \dagger$ & $-0.418(\mathrm{P}<0.001)^{\star}$ & $0.678(\mathrm{P}<0.001) \dagger$ \\
\hline
\end{tabular}

Spearman's correlation coefficients, $\mathrm{p}<0.001$.

*Moderate correlation ( $r=0.35-0.50)$.

†Strong correlation ( $r \geq>0.5)$. 


\section{DISCUSSION}

The translation and cultural adaptation process were not challenging and produced an accurate tChICOAP. The Chinese wordings in all the question and response items are easily understandable, and the questionnaire is simple to complete. The items' CVIs on 'clarity', 'appropriateness' and 'relevance' all achieved the standard of good content validity with CVI of $80 \%$ or above. ${ }^{25}$ In order to ensure, we would evaluate and measure the impact of KOA as in other multinational trials, we followed the translation steps as recommended by the OARSI/OMERACT. ${ }^{13}$

The internal consistency of the tChICOAP total score is excellent, with high Cronbach's alpha and corrected item-total subscale correlation. It is comparable to the original version, (Cronbach's alpha 0.93), the simplified Chinese version (Cronbach's alpha 0.94), and other language versions (Cronbach's alpha 0.82-0.95). ${ }^{5} 1226$ The performance of the test and re-retest reliability is the best among the original version (ICC 0.85), the simplified Chinese version (ICC 0.932) and other language versions such as Turkish (ICC 0.942), Portuguese (ICC 0.92) and Greek (ICC 0.88). ${ }^{5891112}$

Like other language versions, the tChICOAP correlated strongly with the WOMAC pain subscale, as both were constructed to measure osteoarthritic pain. ${ }^{5}{ }^{12} 26$ As expected, the tChICOAP's intermittent and total scores have a strong correlation with SF-12v2 PCS, and only moderate correlation with SF-12v2 MCS. This indicates that the measures are evaluating similar constructs, and the intermittent pain may be the major contributor of reduced physical activity in KOA. The tChICOAP constant pain score correlates moderately with both SF-12v2 PCS and MCS. This can be explained by the complex heterogeneity of pain in KOA. Nociceptive pain, neuropathic pain, central pain sensitisation, pain catastrophizing and the underlying biological activity of joint destruction all contribute to the level of constant pain in KOA, making it difficult to be constructed by SF-12v2. ${ }^{27}$

This is the first traditional Chinese version of ICOAP and the study followed a robust methodology in its translation and validation. The measure of content validity using CVI is a merit, given that CVIs are not available in any of the existing language versions of ICOAP. ${ }^{8-12}$ One limitation of this study is that responsiveness of the tChICOAP was not tested, and a future prospective study will be needed to address this.

In summary, the tChICOAP is a reliable and valid instrument to measure the pain experience of Chinese patients with KOA. The study is going to increase the applicability of ICOAP in research conducted in the Chinese population, and the availability of tChICOAP will facilitate cross-cultural comparison of outcomes in different interventional trials for KOA.

\section{Author affiliations}

${ }^{1}$ The Jockey Club School of Public Health and Primary Care, The Chinese University of Hong Kong, Hong Kong
${ }^{2}$ The Jockey Club School of Public Health and Primary Care, The Chinese University of Hong Kong, Hong Kong

${ }^{3}$ The School of Chinese Medicine, The Chinese Unviersity of Hong Kong, Hong Kong ${ }^{4}$ The Jockey Club School of Public Health and Primary Care, The Chinese University of Hong Kong, Hong Kong

Acknowledgements We would like to thank Dr George K H Leung, the orthopaedic surgeon and associate consultant from the Department of Orthopedic and Traumatology of Tuen Mun Hospital, the Hong Kong Special Administrative Region, for the forward translation of ICOAP. We would like to thank all the participants in the study.

Contributors The following authors had made substantial contributions to the following: the concept and design of the study (RWSS and WW), collection and assembly of data (RS and LC), analysis and interpretation of data (RWSS, DCCC and BHKY), drafting the article (RWSS and SYW), revising critical important intellectual content (RWSS, DCCC, WW, BHKY and SYW). All the authors approved final version of the manuscript.

Funding The study is funded by the Chinese University of Hong Kong Direct Grant for Research 2017 (HKD 56,084). The funding body has no role in the study other than providing funding.

Competing interests None declared.

Patient consent for publication Obtained.

Ethics approval The study complies with the Declaration of Helsinki and has been approved by the Joint Chinese University of Hong Kong, New Territories East Cluster Clinical Research Ethics Committee. (Reference No.: 2016-601).

Provenance and peer review Not commissioned; externally peer reviewed.

Data sharing statement All data generated or analyzed in this study are included in this published article. Extra data can be accessed via the Dryad data repository at http://datadryad.org/ with the doi:10.5061/dryad.30r34f7

Open access This is an open access article distributed in accordance with the Creative Commons Attribution Non Commercial (CC BY-NC 4.0) license, which permits others to distribute, remix, adapt, build upon this work non-commercially, and license their derivative works on different terms, provided the original work is properly cited, appropriate credit is given, any changes made indicated, and the use is non-commercial. See: http://creativecommons.org/licenses/by-nc/4.0/.

\section{REFERENCES}

1. Cross M, Smith E, Hoy D, et al. The global burden of hip and knee osteoarthritis: estimates from the global burden of disease 2010 study. Ann Rheum Dis 2014;73:1323-30.

2. Perrot S, Marty M, Legout V, et al. Ecological or recalled assessments in chronic musculoskeletal pain? A comparative study of prospective and recalled pain assessments in low back pain and lower limb painful osteoarthritis. Pain Med 2011;12:427-36.

3. Rayahin JE, Chmiel JS, Hayes KW, et al. Factors associated with pain experience outcome in knee osteoarthritis. Arthritis Care Res 2014;66:1828-35.

4. Lane NE, Brandt K, Hawker G, et al. OARSI-FDA initiative: defining the disease state of osteoarthritis. Osteoarthritis Cartilage 2011;19:478-82

5. Hawker GA, Davis AM, French MR, et al. Development and preliminary psychometric testing of a new OA pain measure--an OARSI/OMERACT initiative. Osteoarthritis Cartilage 2008;16:409-14.

6. Song J, Chang A, Chang R, et al. Constant and intermittent knee pain and their relationship to physical activity: data from osteoarthritis initiative. Osteoarthritis Cartilage 2017;25:S371-S372.

7. Gossec L, Paternotte S, Maillefert JF, et al. The role of pain and functional impairment in the decision to recommend total joint replacement in hip and knee osteoarthritis: an international crosssectional study of 1909 patients. Report of the OARSI-OMERACT Task Force on total joint replacement. Osteoarthritis Cartilage 2011;19:147-54.

8. Erel S, Șimșek İE, Özkan H. Analysis of the reliability and validity of the Turkish version of the intermittent and constant osteoarthritis pain questionnaire. Acta Orthop Traumatol Turc 2015;49:508-12.

9. Gonçalves RS, Cabri J, Pinheiro JP, et al. Cross-cultural adaptation and validation of the Portuguese version of the intermittent and constant osteoarthritis pain (ICOAP) measure for the knee. Osteoarthritis Cartilage 2010;18:1058-61. 
10. Kessler S, Grammozis A, Günther KP, et al. [The intermittent and constant pain score (ICOAP) - a questionnaire to assess pain in patients with gonarthritis]. Z Orthop Unfall 2011;149:22-6.

11. Manolarakis GE, Kontodimopoulos N, Sifaki-Pistolla D, et al. Establishing the psychometric properties of the icoap questionnaire through intra-articular treatment of osteoarthritic pain: implementation for the greek version. Arthritis 2016;2016:1-11.

12. Zhang C, Liu DH, Qu YL, et al. Transcultural adaptation and validation of the Chinese version of the intermittent and constant osteoarthritis pain (ICOAP) measure in patients with knee osteoarthritis. Osteoarthritis Cartilage 2017;25:506-12.

13. Maillefert JF, Kloppenburg M, Fernandes L, et al. Multi-language translation and cross-cultural adaptation of the OARSI/OMERACT measure of intermittent and constant osteoarthritis pain (ICOAP). Osteoarthritis Cartilage 2009;17:1293-6.

14. Altman RD. Criteria for classification of clinical osteoarthritis. J Rheumatol Suppl 1991;27:10-12.

15. Moreton BJ, Wheeler M, Walsh DA, et al. Rasch analysis of the intermittent and constant osteoarthritis pain (ICOAP) scale. Osteoarthritis Cartilage 2012;20:1109-15.

16. McAlindon TE, Driban JB, Henrotin Y, et al. OARSI clinical trials recommendations: design, conduct, and reporting of clinical trials for knee osteoarthritis. Osteoarthritis Cartilage 2015;23:747-60.

17. Bellamy N, Buchanan WW, Goldsmith $\mathrm{CH}$, et al. Validation study of WOMAC: a health status instrument for measuring clinically important patient relevant outcomes to antirheumatic drug therapy in patients with osteoarthritis of the hip or knee. J Rheumatol 1988;15:1833-40.
18. Xie F, Li SC, Goeree R, et al. Validation of Chinese Western Ontario and McMaster Universities Osteoarthritis Index (WOMAC) in patients scheduled for total knee replacement. Qual Life Res 2008;17:595-601.

19. Lam C, Wong C, Lam E, et al. Population norm of Chinese (HK) SF12 health survey-version 2 of Chinese adults in Hong Kong. Hong Kong Practitioner 2010;32:77-86.

20. Lam CL, Tse EY, Gandek B. Is the standard SF-12 health survey valid and equivalent for a Chinese population? Qual Life Res 2005;14:539-47.

21. Bonett DG. Sample size requirements for estimating intraclass correlations with desired precision. Stat Med 2002;21:1331-5.

22. Terwee CB, Bot SD, de Boer MR, et al. Quality criteria were proposed for measurement properties of health status questionnaires. J Clin Epidemiol 2007;60:34-42.

23. Fayers PM, Machin D. Quality of life: the assessment, analysis and interpretation of patient-reported outcomes: John Wiley \& Sons, 2013.

24. Shrout PE, Fleiss JL. Intraclass correlations: uses in assessing rater reliability. Psychol Bull 1979;86:420-8.

25. Lynn MR. Determination and quantification of content validity. Nurs Res 1986;35:382-6.

26. Mehta SP, Sankar A, Venkataramanan V, et al. Cross-cultural validation of the ICOAP and physical function short forms of the HOOS and KOOS in a multi-country study of patients with hip and knee osteoarthritis. Osteoarthritis Cartilage 2016;24:2077-81.

27. Perrot S. Targeting pain or osteoarthritis? Implications for optimal management of osteoarthritis pain. Pain 2016;24. 